\title{
A Framework for Optimal Assessment of Planning Investments in Urban Water Systems
}

\author{
Rodolfo García-Flores ${ }^{1}$, Magnus Moglia ${ }^{2}$, and David Marlow ${ }^{3}$ \\ ${ }^{1}$ CSIRO Digital Productivity and Services Flagship, Clayton South, Australia \\ Rodolfo.Garcia-Flores@csiro.au \\ ${ }^{2}$ CSIRO Land and Water Flagship, Highett, Australia \\ Magnus.Moglia@csiro.au \\ ${ }^{3}$ Wiser Analysis, Keysborough, Australia \\ David.Marlow@wiseranalysis.com
}

\begin{abstract}
The functionality expected by governments and citizens from urban water management systems (UWMS) has evolved in time from delivering basic services to enabling complex issues such as healthy ecosystems, environmental sustainability, and economic growth. Alongside these changing expectations, the pressure on policy makers to fulfill disparate performance metrics with diminishing resources is increasing. In this paper, we introduce the Water Assets and Infrastructure Network Decision Support (WAND) framework for modelling and planning urban water systems with the aim of assisting medium to long-term investment decisions. The framework combines economic performance measures with liveabililty and sustainability, and uses optimisation as a crucial component. To demonstrate its feasibility, we present a prototype environmental software system built upon the principles of legibility, adherence to engineering conventions, and extensive unit testing. We use the prototype system to analyse a model of a hypothetical urban water system formed by two coupled water networks, one for freshwater and one for stormwater collection, and which handles six different commodities. Our results suggest to planners the optimal combination of planning investments while considering capacities, service levels and network operating conditions.
\end{abstract}

Keywords: urban water planning, infrastructure planning, decision making for water networks.

\section{$1 \quad$ Introduction}

The Water Services Association of Australia (WSAA, 2013) estimate that the urban water sector delivers services to over 20 million Australians in more than 9 million connected properties. It manages over AUD \$120 billion in assets and between 2006-07 and 2011-12 capital expenditure was estimated at over \$33 billion. Operational expenditure in 2011-12 was estimated at $\$ 7.2$ billion. The urban water sector is a significant part of the Australian economy. More than that, urban water infrastructure represents a significant capital stock and future generations will inherit the cumulative impact of our ongoing investment decisions (Nolan, 2007; Marlow et al., 2010). 
The core urban water services involve the management of three water streams: water supply, sewage (and used water), and stormwater. Traditionally, each of these streams has been managed separately, but pressures on these systems have, however, grown over time and there is an increasing clash between the demand for and limits of water resources. This clash results in ecological, economic and cultural 'strains' (Vlachos and Braga, 2001), which have led various authors to suggest that the current model of water service provision is not sustainable, especially when considered in light of future uncertainties such as climate change and population growth (Ashley et al. 2003; Milly et al. 2008; Wong and Brown 2008).

From a practical perspective, innovations are being introduced into systems dominated by traditional centralised solutions to produce hybrid systems that combine decentralized green infrastructure systems, such as storm water harvesting, and traditional capital-intensive infrastructure. Balancing the costs, benefits and risks of both approaches requires enhanced capacity to predict the future and consider multiple tradeoffs. This to a large extent becomes an optimisation problem, which involves effective management of infrastructure assets. Further discussion of such management strategies is provided by Maheepala et al. (2010) or Marlow et al. (2013).

Regarding optimal design of water networks, Daganzo (2012) considered public infrastructure systems where the policy-making body chooses prices and system design by maximising society's welfare. This combined problem was decomposed into subproblems, and optimal operation was induced by structuring payments adequately. Bieupoude et al. (2012) used a geometric optimisation method known as "constructal" design to optimize water distribution network architectures subject to operational water quality constraints. Marinoni et al. (2011) developed a method based on mathematical programming to determine the impact of development on a waterway that receives treated water based on water quality criteria, and applied it to Greater Sydney Metropolitan Area.

There exist environmental software systems that inform investment in UWMS, including a small number of commercial products which inform optimal investments in urban water systems. However, none of these consider all the metrics simultaneously. Among the most widely used are PIONEER ${ }^{1}$ (Lumbers et al., 2010), and WilCO ${ }^{2}$ (Burns et al., 2012), which are suites of models built as environments for planning water infrastructure. Both WiLCO and PIONEER have been developed in the UK institutional and regulatory context in mind, though their parent companies claim that they can be extended to the requirements of other sectors. The modelling undertaken within WILCO and PIONEER focuses on water and wastewater assets, which are considered in isolation from each other, and trade-offs are thus analysed within each service area, but not across service areas. Furthermore, neither WiLCO nor PIONEER were designed to represent the urban water system as a whole, so they do not consider wastewater, drinking water and stormwater in an integrated manner.

In this paper, we introduce the Water Assets and Infrastructure Network Decision Support (WAND) framework, which has the aim of assisting medium- to long-term investment decisions, and relies on optimisation as a crucial component. The proof-ofconcept solves a mathematical model of a hypothetical UWMS. Our results suggest to

\footnotetext{
${ }^{1}$ http: //www. tynemarch.co.uk/products/pioneer/index.shtml, accessed on February 28, 2014.

${ }^{2}$ http: / / www . seamsltd. com, accessed on February 28, 2014.
} 
planners the optimal combination of investments, while considering capacities, service levels and operating conditions for sets of equipment and facilities.

\section{The WAND Framework}

The WAND framework (Figure 1) is based on the fact that baseline performance as reflected in the system of representative metrics (related to liveability, sustainability and productivity) will vary over time due to natural changes, including the impact of asset deterioration and other natural factors such as of climate change. Performance will also be influenced by anthropogenic factors such as changes in customer requirements/expectations, regulatory requirements, population growth or macro-economic development. The impact of these changes on system performance can only be countered by making investments in capital and non-capital interventions; informing these is the purpose of the core engine of WAND, which relies on optimisation to reduce the gap between actual and target performance. To feed the optimiser, information is required on the policies and strategies to implement and the effectiveness of the associated intervention options. The optimal investment decisions, selected from a feasible option space, alter the system as part of a feedback loop that operates at strategic, tactic and operational time scales. This helps form a self-similar model, in the sense that it is as representative to consider specific service areas as it is to consider the complete urban water system. In fact, in theory the framework could be expanded to include all urban systems at the three key decision scales and provide systemic insights into the impact of investments across a whole range of service provision areas.

The WAND prototype software system introduced in this paper implements the tasks of the core engine, and its purpose is to assess the tradeoffs on livability, sustainability and productivity associated with different portfolios of investment within a single framework. The prototype handles investments by distinguishing between asset operation, replacement, maintenance and construction.

To illustrate the purpose of the WAND environmental software system, we address on the problem of urban water runoffs. As cities grow the landscape changes and there is an increase in the area of land that is covered by impervious surfaces. This means that, when rain falls on the city, much of the water that would otherwise have penetrated into the soil now gathers as urban runoff. This changes the flow patterns in rivers and creeks, with further impacts on ecosystems and erosion of river banks, as well as increasing the risk of urban flooding with consequent societal costs. Furthermore, the runoff in cities goes directly to receiving waters without treatment (Burns et al., 2012), becoming a significant source of pollution. WAND addresses runoffs by assisting investment decisions in:

- Capture and use of stormwater; i.e. stormwater or rainwater harvesting (Sharma et al., 2009). This includes the treatment of urban runoff as per local regulations.

- Water Sensitive Urban Design features (Wong, 2006), which are helpful in order to achieve a more natural water cycle and provide additional treatment of urban runoff, such as stormwater bioretention systems and constructed wetlands. These are also known as green infrastructure. 


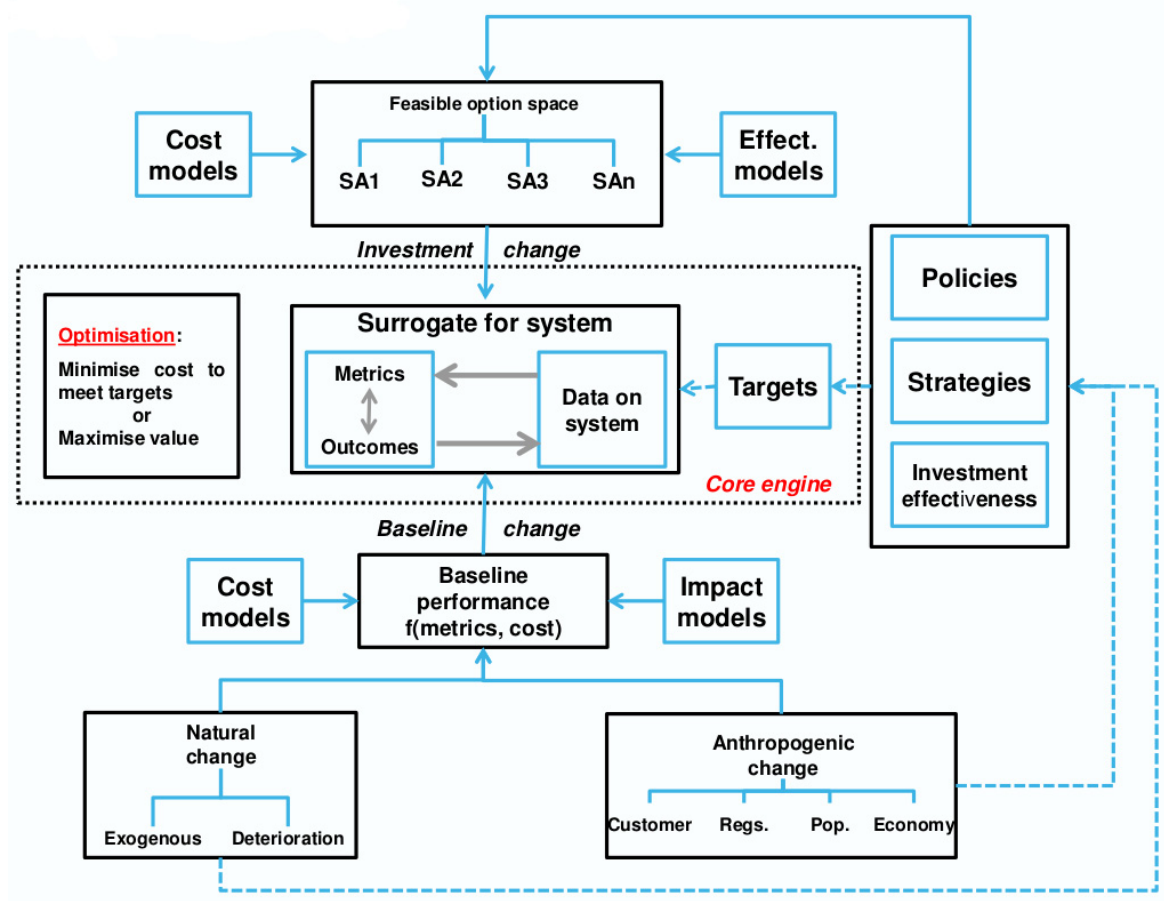

Fig. 1. The Water Assets and Infrastructure Network Decision Support (WAND) framework

\section{Computational System}

The optimiser in the WAND framework was implemented in Clojure ${ }^{3} 1.5$ and CPLEX $^{4} 12.4$ with an Excel interface, as the UML 2 component diagram (Jacobson et al., 1999) in Figure 2 shows. Clojure is a compiled dynamic programming language of the LISP family built for the Java Virtual Machine (JVM) that has features that make it an attractive alternative to code the solution of problems that depend crucially on a correct mathematical representation. First, it has all the flexibility and power of LISP, but without the burden of backward compatibility with historical versions (Halloway, 2009). Second, it connects seamlessly to the mainstream infrastructure provided by Java by embracing the JVM. It does not attempt to build wrappers around Java, but tries to access it idiomatically, enabling the programmer to leverage on his past programming experience and on the huge amount of legacy code available for Java. Additional advantages include good concurrency support, a small core, laziness and conditions for error handling. Our WAND implementation makes extensive use of the symbolic features of LISP, for example for indexing of variables, making the order of the indexes irrelevant. This is extremely useful because the client's expert

3 http://clojure.org/, accessed on the 8 of April of 2013.

4 http://www-01.ibm.com/software/integration/optimization/cplexoptimizer/, accessed on the 8 of April 2013. 
knowledge is often based in the particular situations of individual water management resources, and using names is easier to understand than referring to elements by looking up tables of indexes.

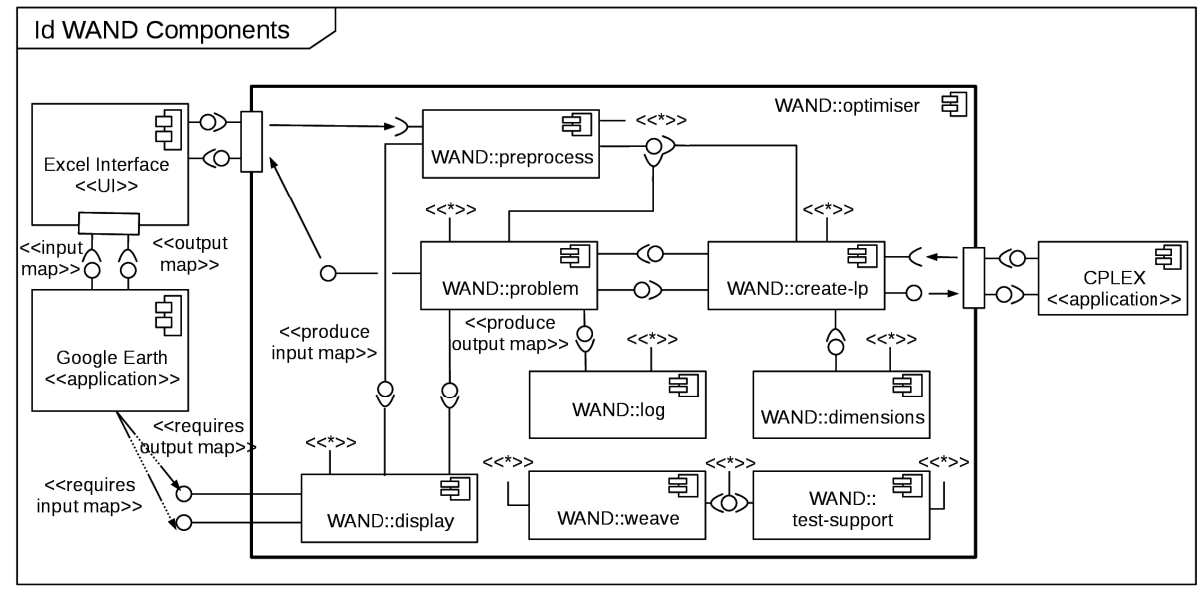

Fig. 2. UML 2 component diagram of the WAND optimiser

We developed the system with clarity as the core requirement. We aimed at keeping the problem as close to its mathematical representation as possible. To achieve this goal, we incorporated the following development principles:

1. Literate approach. When coded in literate style, a program should explain a problem and its solution to a human reader because its concepts have been introduced in an order that is best for human understanding (Knuth, 1984). This implies that software writing has more to do with the craft of writing, including its gradual process of improvement and refinement of ideas, than with merely laying down instructions for a machine to perform. The project was designed with namespace WAND: : weave to process the documentation by weaving as introduced by Knuth (1984). All documentation in Clojure is stored as metadata, which in our system is retrieved by the functions in this namespace and "woven" (i.e., formatted) into $\mathrm{L}^{\mathrm{A}} \mathrm{T}_{\mathrm{E}} \mathrm{X}$ source. The documentation in the woven document is divided in sections, each of which corresponds to a namespace in the optimiser. Each section includes a description of the namespace's functions and variables. $\mathrm{L}^{\mathrm{A}} \mathrm{T}_{\mathrm{E}} \mathrm{X}$ enables the inclusion of formulas or typesetting commands as part of the documentation.

2. Unit test design. Unit testing takes advantage of the structure that Clojure gives to metadata. The : test field of the metadata enables the storage of a test function as part of a variable. By retrieving the names of all functions (i.e., data members that have argument lists) in a namespace, it is possible to generate lists of functions to be tested automatically, greatly facilitating unit testing. An extensive and automated unit testing namespace was implemented in WAND : : test-support. 
3. Dimensional analysis. In our experience, the lack of support for dimensional analysis has been the source of multiple problems in the past. We decided to take advantage of existing code from the JScience ${ }^{5}$ library. Re-using Java code is encouraged in languages developed for the Java Virtual Machine, and is a particularly simple task in Clojure. Because dimensional analysis is one of the most basic engineering tools, the selected framework should be easy to reuse (namespace WAND : : dimensions).

Namespace WAND : : preprocess translates Excel input data into a data structure that can be handled by the optimiser. This is used by WAND : problem to produce the mathematical formulation, using the support functions stored in WAND : : create-1p. Namespaces WAND: : log and WAND: : display keep a log of calculation progress and format the input and output data as KML maps, respectively. For the external components, the Excel interface captures input data regarding existing and proposed infrastructure, demand, intake levels and capacities, and retrieves the results in spreadsheet format. It also has the capacity to display input and solutions as maps in KML format, by invoking Google Earth ${ }^{6}$. CPLEX is a commercial solver for mixed integer linear programming problems.

Although there is great variety of tools available for development of environmental software systems (Argent and Houghton, 2001), we tried to keep the number of tools to a minimum to enhance clarity. The structure of the WAND optimiser in Figure 1 is the product of assimilating previous and successful experiences in coding similar optimisation problems (Higgins et al.; 2013, García-Flores et al., 2014) using the above-mentioned coding principles. The main advantages we perceive from the approach to software development adopted for WAND include shorter length of source code, legibility, reliability and facility to produce documentation. Most importantly, because the code is close to the notation of the mathematical formulation, we also expect WAND's optimisation module to be refined further and reused in future projects.

\section{Example - Melbourne Urban Water System}

This example illustrates the implementation of the framework to the Melbourne water system (Figure 3), which consists of two coupled water distribution networks.

- The fresh water network, which also incorporates wastewater streams, is shown in solid arrows and transports fresh water (that is, water for indoor and outdoor use) from reservoirs (sources marked with $s_{f}$ in Figure 3 ) to the clients in Melbourne's suburbs (marked $r$ ). After use, the waste water collected is sent to treatment plants, marked $u_{f}$, and part of it is used again, (this is shown as double arrows to indicate separate pipelines) and part is disposed of in Port Philip Bay (shown as a gray block arrow). The "return" direction of the double arrows represents what is known as "purple pipes", which is a separate network of limited reach. Most areas do not have purple pipes going to them.

\footnotetext{
${ }^{5}$ http: / / jscience. org/, accessed on the 30 of October 2014.

${ }^{6}$ https: / /www. google.com/earth/, accessed on the 30 of October 2014.
} 
- The stormwater collection network, shown in dashed arrows, collects rain water in catchments $s_{m}$ in different points in the city. After some treatment in sites marked as $u_{m}$ (wetlands, for example), part of it is used, depending on the setup, as indoor or outdoor water (or indoor only or outdoor only), and part of it ends in Port Philip Bay.

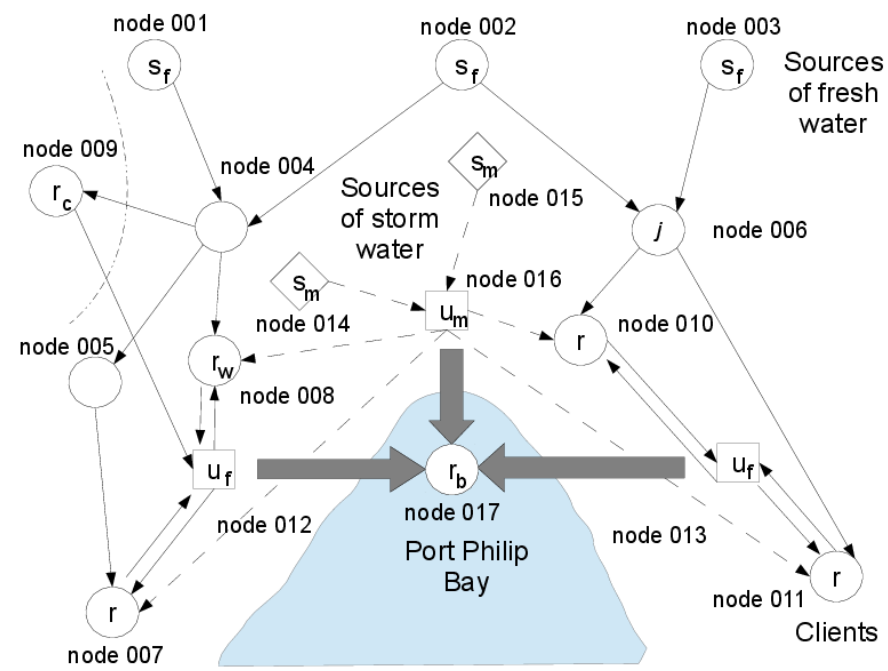

Fig. 3. The Greater Melbourne Water System

One of the objectives of the treatment facilites $u_{f}$ and $u_{m}$ is to reduce the amount of nutrients thrown into the bay. Irrigation areas can be considered sinks, and green infrastructure is modelled as a subset of treatment facilities $u_{m}$, which comprise wetlands, vegetated swales and biofiltration. The success of these facilities depends on their ability to store, retain or detain spill-overs, which means that they should also be modelled as reservoirs. Green infrastructure has a positive impact on stormwater flows in different areas. In the model, sewer overflows need to be penalised, whereas stormwater overflows need to be managed.

The WAND model considers six commodities and their transformations:

- Indoor water is mostly potable water, but some of the indoor water use may be covered by non-potable sources, i.e., not treated to class A standard.

- Outdoor water is mostly irrigation water. It travels from treatment facilities $u_{m}$ to clients $r$, and from treatment plants $u_{f}$ back to clients $r$, in both cases to be used as outdoor water. In the path from $u_{f}$ to $r$, outdoor water is really treated waste water. The final destination of outdoor water is the client nodes.

- Fresh water is an aggregate of indoor and outdoor water. It travels from sources of fresh water $s_{f}$ to households $r$. At the households, the water becomes indoor or outdoor, depending on its use.

- Stormwater is sent from stormwater catchments $s_{m}$ to treatment facilities $u_{m}$. Stormwater can only be used for outdoor purposes. 
- Waste water is sent from clients $r$ to water treatment plants $u_{f}$.

- Discharge water is the water returned to the environment into the bay $r_{b}$.

The problem is formulated as a multi-period mixed-integer linear program whose aim is finding the optimal topology and capacities of pipelines connecting the nodes of the water network. This is done by minimising the total costs (i.e., the objective function), expressed as the sum of operation costs (including spillage costs and the costs of exceeding the control limits of sites that act as reservoir), replacement, maintenance and construction costs of all infrastructure assets.

Along the time horizon, the solution of the problem provides information about facility and pipeline segment replacement, upgrade and new construction. The constraints of the problem describe the conservation of flow at facilities and the conversion between water commodities. Some of the facilities are modeled as reservoirs, such as the waste water treatment facilities and green infrastructure (e.g., wetlands). These facilities need constraints with an upper capacity limit, which, if violated, (that is, if the facility overflows) are penalized in the objective function. Sources and stormwater catchments are facilities that provide an influx of fresh and stormwater, respectively, into the system, based on experts' forecasts and which also act as reservoirs, but are not penalised for spillage.

\section{$5 \quad$ Results and Discussion}

The planning horizon considered was from 2014 to 2019, in annual periods, and the tested scenarios were:

1. The creation of a new suburb in 2017 in node 009 with the consequent increase in fresh water demand, together with a linear increase in demand of node 011 from $481 \mathrm{ML}$ of indoor use water per year in 2014 to $1000 \mathrm{ML}$ in 2019 in node 011 . All pipeline segments start with a diameter of $150 \mathrm{~mm}$, except for the segments connecting the network to node 009, which do not exist at the beginning of the time horizon.

2. A "business as usual" scenario where no new suburb is projected and no increase in demand for node 011 is foreseen.

The demands of the clients to test in the scenario are shown in Table 1; the assumed available technologies and their capacities, which represent the investment options, are listed in Table 2. The calculation parameters are listed in Table 3.

Table 1. Demands of clients in the Greater Melbourne case study in ML/year

\begin{tabular}{|l|r|r|}
\hline Node (clients) & Indoor water demand & Outdoor water demand \\
\hline Node 007 & 1326.151 & 241.092 \\
\hline Node 008 & 648.180 & 90.411 \\
\hline Node 009 & 165.758 (after 2017$)$ & 23.121 (after 2017 ) \\
\hline Node 010 & 117.47 & 16.385 \\
\hline Node 011 & 481.356 (increasing to 1000 by 2019) & 67.142 \\
\hline
\end{tabular}


Table 2. Available technologies to install in nodes and pipeline segments

\begin{tabular}{|l|l|}
\hline Infrastructure type & Available technologies \\
\hline Nodes & Site $200 \mathrm{ML}$, Site $500 \mathrm{ML}$, Site $1000 \mathrm{ML}$, Site $1500 \mathrm{ML}$. \\
\hline Pipeline segments & Pipe $150 \mathrm{~mm}$, Pipe $250 \mathrm{~mm}$, Pipe $350 \mathrm{~mm}$ \\
\hline
\end{tabular}

Table 3. Penalisation parameters to enforce supply and operational levels in reservoirs

\begin{tabular}{|l|l|l|l|}
\hline $\begin{array}{l}\text { Penalty for failing } \\
\text { to deliver indoor } \\
\text { water }\end{array}$ & $\begin{array}{l}\text { Penalty for failing } \\
\text { to deliver outdoor } \\
\text { water }\end{array}$ & $\begin{array}{l}\text { Penalty for violating } \\
\text { control limit in storm- } \\
\text { water collection point }\end{array}$ & $\begin{array}{l}\text { Penalty for overflow- } \\
\text { ing stormwater collec- } \\
\text { tion point }\end{array}$ \\
\hline$\$ 10.0 \mathrm{M} / \mathrm{ML}$ & $\$ 10.0 \mathrm{M} / \mathrm{ML}$ & AUD $\$ 1000 / \mathrm{ML}$ & AUD $\$ 0.1 \mathrm{M} / \mathrm{ML}$ \\
\hline
\end{tabular}

We obtained all the following results in a 64-bit Intel Xeon CPU with 2 processors of eight cores $(2.27 \mathrm{GHz})$ each and $48 \mathrm{~GB}$ of RAM. The linear program problem has 22,542 real variables, of which 14,880 are binary and 7,762 are real, and 50,421 constraints. A typical run takes around two hours and forty minutes to complete. Tables 4 and 5 show the suggested investments under scenario 1. These are, first, the construction of a fresh water pipeline and on-site infrastructure for node 009 to fulfill the new demand, as expected. Second, the increase in capacity of the pipelines connected to the waste water treatment plant in node 012 . These also occur under scenario 2 , as the initial pipe diameter assumed for the flows to node 012 is insufficient. Third, we can see the increase in capacity of the pipelines that connect node 011 to node 013 , due to the increase in demand in node 011 . Finally, we note in Table 5 that the optimiser suggests a "downgrade" of the fresh water source in node 002 . This is probably not an action that a policy maker would take, but in this case we obtain this result because the cost of downgrading is not high enough. The decision maker can easily change the value of this parameter. Finally, scenario 2 turns out to be $11.3 \%$ more costly than "business as usual".

Table 4. Results for the upgrade and construction of new pipeline infrastructure

\begin{tabular}{|l|l|l|l|l|l|}
\hline $\begin{array}{l}\text { Origin } \\
\text { node }\end{array}$ & $\begin{array}{l}\text { Destination } \\
\text { node }\end{array}$ & Commodity & Year & $\begin{array}{l}\text { Old infrastruc- } \\
\text { ture }(\mathrm{mm})\end{array}$ & $\begin{array}{l}\text { New infra- } \\
\text { structure }(\mathrm{mm})\end{array}$ \\
\hline 012 & 007 & Fresh water & 2015 & 150 & 350 \\
\hline 012 & 008 & Fresh water & 2015 & 150 & 350 \\
\hline 013 & 011 & Fresh water & 2015 & 150 & 350 \\
\hline 007 & 012 & Waste water & 2015 & 150 & 350 \\
\hline 008 & 012 & Waste water & 2015 & 150 & 350 \\
\hline 011 & 013 & Waste water & 2015 & 150 & 350 \\
\hline 004 & 009 & Fresh water & 2017 & None & 350 \\
\hline
\end{tabular}

Table 5. Results for the upgrade and construction of new node infrastructure

\begin{tabular}{|l|l|l|l|l|l|}
\hline Node & Node type & Commodity & Year & $\begin{array}{l}\text { Old infrastructure } \\
(M L)\end{array}$ & $\begin{array}{l}\text { New infrastruc- } \\
\text { ture }(M L)\end{array}$ \\
\hline 002 & Source & Fresh water & 2016 & 1500 & 500 \\
\hline 002 & Source & Fresh water & 2017 & 500 & 200 \\
\hline 004 & Junction & Fresh water & 2017 & None & 200 \\
\hline 009 & Client & Fresh water & 2016 & None & 200 \\
\hline
\end{tabular}




\section{Summary, Conclusions and Future Applications}

The expectations from urban water management systems have grown to include not only the provision of basic services, but also enabling healthy ecosystems, environmental sustainability, and economic growth. To achieve these goals, we have introduced the Water Assets and Infrastructure Network Decision Support framework. WAND uses optimisation and is built using the principles of legibility, adherence to engineering conventions, and extensive unit testing. To demonstrate its feasibility, we applied a prototype software system to a model of an urban water network that handles six different water commodities. The results suggest to planners the optimal combination of planning investments, while considering capacities, service levels and network operating conditions.

The main advantages we perceive from using standard engineering conventions (such as dimensional analysis) and the coding principles of literate programming and unit test design are, first, a shorter length of source code when compared to similar $\mathrm{C}++$ developments; second, it is easier to produce documentation; and third, increased legibility and reliability. The main strength of the WAND optimiser is that it attempts to keep source code as close to the mathematical representation of the problem as possible by taking advantage of LISP's flexibility. This facilitates debugging and enables new members of the development team to "hit the ground running". On the downside, the disadvantages of our approach are the slow execution times when compared to $\mathrm{C}++$ code and the unavoidable learning curve if the analyst is not familiar with LISP syntax. Nevertheless, we expect WAND's optimisation module to continue being refined and reused in future projects, although concepts such as deterioration are yet to be incorporated.

\section{References}

1. Argent, R.M., Houghton, B.: Land and water resources model integra-tion: software engineering and beyond. Advances in Environmental Research 5, 359-359 (2001)

2. Ashley, R.M., Blackwood, D.J., Butler, D., Davies, J.A., Jowitt, P., Smith, H.: Sustainable decision making for the UK water industry. Engineering Sustainability 156(ES1), 41-49 (2003)

3. Bieupoude, P., Azoumah, Y., Neveu, P.: Optimization of drinking water distribution networks: Computer-based methods and constructal design. Computers, Environment and Urban Systems 36(5), 434-444 (2012)

4. Burns, M.J., Fletcher, T.D., Walsh, C.J., Ladson, A.R., Hatt, B.E.: Hydrologic shortcomings of conventional urban stormwater management and opportunities for reform. Landscape and Urban Planning 105(3), 230-240 (2012)

5. Daganzo, C.: On the design of public infrastructure systems with elastic demand. Transportation Research Part B: Methodological 46(9), 1288-1293 (2012)

6. García-Flores, R., Higgins, A., Prestwidge, D., McFallan, S.: Optimal location of spelling yards for the northern Australian beef supply chain. Computers and Electronics in Agriculture 102, 134-145 (2014)

7. Halloway, S.: Programming Clojure. The Pragmatic Programmers (2009) 
8. Higgins, A., Watson, I., Chilcott, I., Zhou, M., García-Flores, R., Eady, S., McFallan, S., Prestwidge, D., Laredo, L.: A framework for optimizing capital investment and operations in livestock logistics. Rangeland Journal 35, 181-191 (2013)

9. Rumbaugh, J., Jacobsen, I., Booch, G.: The Unified Software Development Process. Addison Wesley (1999)

10. Knuth, D.E.: Literate programming. The Computer Journal 27(2), 97-111 (1984)

11. Lumbers, J., Conway, T., Fynn, T., Heywood, G.: Optimal asset management planning: advances in water mains and sewers analysis within a new modelling environment. Water Asset Management International 6, 10-13 (2010)

12. Maheepala, S., Blackmore, J., Diaper, C., Moglia, M., Sharma, A., Kenway, S.: Integrated Urban Water Management Planning Manual. Denver, CO, Water Research Foundation (2010)

13. Marinoni, O., Higgins, A., Coad, P., Navarro, J., McPherson, R.: Directing urban development to the right places: Assessing the impact of urban development in an estuarine environment. In: Chan, F., Marinova, D., Anderssen, R. (eds.) MODSIM2011 19th International Congress on Modelling and Simulation, pp. 1902-1908. Modelling and Simulation Society of Australia and New Zealand (2011)

14. Marlow, D.R., Beale, D.J., Burn, S.: A pathway to a more sustainable water sector: sustainability-based asset management. Water Science \& Technology 61(5), 1245-1255 (2010)

15. Marlow, D.R., Moglia, M., Cook, S., Beale, D.J.: Towards sustainable urban water management: A critical reassessment. Water Research 47(20), 7150-7161 (2013)

16. Milly, P.C.D., Betancourt, J., Falkenmark, M., Hirsch, R.M., Kundzewicz, Z.W., Lettenmaier, D.P., Stouffer, R.J.: Climate change: Stationarity is dead: Whither water management? Science 319, 573-574 (2008)

17. Mitchell, V.G.: Applying Integrated Urban Water Management Concepts: A Review of Australian Experience. Journal of Environmental Management 37(5), 589-605 (2006)

18. Nolan, B.: Funding Water and Wastewater Projects: Growing Communities Seek Strategic Alternatives. American Water Works Association Journal 99(5), 42-42 (2007)

19. Sharma, A.K., Grant, A.L., Grant, T., Pamminger, F., Opray, L.: Environmental and Economic Assessment of Urban Water Services for a Greenfield Development. Environmental Engineering Science 26(5), 921-934 (2009)

20. Maksimovic, C., Tejada-Guibert, J.A.: Frontiers in urban water management, deadlock or hope. In: Vlachos, P.E., Braga, P.B. (eds.) Chapter 1: The challenge of urban water management, pp. 1-34. IWA Publishing, London (2001)

21. Walsh, C.J., Fletcher, T.D., Ladson, A.R.: Stream Restoration in Urban Catchments through Redesigning Stormwater Systems: Looking to the Catchment to Save the Stream. Journal of the North American Benthological Society 24(3), 690-705 (2005)

22. Wong, T., Brown, R.: Transitioning to Water Sensitive Cities: Ensuring Resilience through a new Hydro-Social Contract. In: 11th International Conference on Urban Drainage, Edinburgh, Scotland, UK, vol. 10 (2008)

23. Wong, T.H.F.: An Overview of Water Sensitive Urban Design Practices in Australia. Water Practice \& Technology 1(1) (2006)

24. WSAA, The future of the urban water industry. Submission to the National Water Commission's Triennial Assessment (2013) 